Research Article

\title{
Container Slot Allocation for Time-Sensitive Cargo in Maritime Transportation: A One-Phase Model with consideration of Port Congestion
}

\author{
Qi Yao $\mathbb{D}^{1},{ }^{1}$ Lu Xu $\mathbb{D},{ }^{2}$ and Qin Zhang $\mathbb{D}^{1}$ \\ ${ }^{1}$ School of Management, Wuhan College, Wuhan 430212, China \\ ${ }^{2}$ School of Information Management, Central China Normal University, Wuhan 430079, China \\ Correspondence should be addressed to Qin Zhang; 9231@whxy.edu.cn
}

Received 17 October 2020; Revised 18 November 2020; Accepted 19 January 2021; Published 12 February 2021

Academic Editor: Fabio Tramontana

Copyright ( 2021 Qi Yao et al. This is an open access article distributed under the Creative Commons Attribution License, which permits unrestricted use, distribution, and reproduction in any medium, provided the original work is properly cited.

This paper studies a container slot allocation problem with dynamic pricing for time-sensitive cargo considering port congestion. Time-sensitive cargo calls for express delivery as soon as possible, and hence a new pricing pattern is proposed considering port congestion. To solve the slot allocation with dynamic pricing issue, a one-phase allocation model which is from different points of view on slot allocation strategy is proposed to formulate this problem. Finally, numerical examples are carried out to test the applicability of the proposed model and solution algorithm.

\section{Introduction}

In recent years, with the rapid development of economic globalization, the maritime industry has got steady growth [1], among which the container transportation gets the most rapid growth for its large scale, security, convenience for multimodal transport, and so on $[2,3]$. In 2015, the total container trade volume amounted in 175 million twentyfoot equivalent units (TEUs) [4]. Containerized cargoes from different shippers are transported by container shipping lines from their origin port to destination port (simply noted as O-D pair). With the fierce competition in market, it is significantly vital for shipping lines to assign its finite ship capacity resource measured by TEUs to container slot demand in different O-D pairs so as to complete customer's demand efficiently as well as to maximize the transportation benefits. Therefore, the slot allocation is an issue for the shipping lines to be concerned about, and it also attracts the attention of researchers.

Another issue which should be concerned by the shipping line is the cargo's call for transit time, and we call this category of cargo as time-sensitive cargo. With the improvement of people's living standard, more attention is put on products' quality, especially for perishable products like fruits, fish, flowers, crabs, and meat. In order to keep the quality of the time-sensitive cargoes, customers expect to obtain them as soon as possible, which indicates that the time-sensitive cargoes are expected to be express delivered and even the payment for such express delivery is high. The high payment motivates a shipping company to receive the delivery of time-sensitive cargoes. Moreover, if the cargoes are delivered to shippers before the due date of shipping, the shippers can have more time to deliver the product to customers before expiration with high quality so as to obtain extra reward; accordingly, the actual freight rate should increase, which is another motivation as well. Of course, if the cargoes are arrived at their destination after the negotiated date, the shipping company has to be penalized. Hence, whether the time-sensitive cargoes can be delivered on time or not is a key issue to be considered by the shipping company. The delivery time for a cargo consists of the shipping time on sailing and staying time in port which mainly includes the waiting time and service time for loading/unloading at port. From the point of shipping line, the sailing time can be controlled by adjusting the vessel's sailing speed without considering the influence of extreme 
conditions. However, the staying time in port is not easy to predict by the shipping line due to some uncontrollable common factors in terminal operations. The most common uncontrollable factor is port congestion, caused by schedule unreliability in terminals [5], source limitation such as berths, quay cranes, and internal transport trucks $[6,7]$, ship collisions or ship groundings [8], and so on, all of which make the ships to wait on anchor point. Therefore, when the shipping line intends to sign a contract of shipping timesensitive cargoes with the shippers, the port congestion is an issue that cannot be ignored in the estimation of delivery time because the shipping line needs to leave enough suffer time for the delay at port.

Therefore, the container slot allocation problem of timesensitive cargoes proposed in this paper is different from that for general cargoes, which indicates that the methodologies in the existing researchers studied for general cargoes cannot be directly applied for the proposed problem in this paper. We need to develop a new one for our problem, which is the work we intend to take effort in this paper.

The remainder of this paper is organized as follows. Section 2 is a review of previous research. Section 3 elaborates the container slot allocation of time-sensitive cargo considering time limit and port congestion. Section 4 develops the two models for the proposed problem, which are one-phase allocation model and two-phase allocation model, respectively. Solution algorithm is proposed in section 5, in which the chance constrained programming (CCP) method is introduced to solve the models. Section 6 uses a numerical example to evaluate the models and solution algorithm proposed in the study. Finally, section 7 concludes the study and provides recommendations for future work.

\section{Literature Review}

Many researches have been studied on the slot allocation problem in container shipping, and most of the studies focused on network planning and path optimization, dynamic pricing based on revenue management, multimodal transportation, and so on. While few literatures focus on the particularity of shipping cargo, such as the special requirements of goods on the due time.

\subsection{Literature on Slot Allocation, Dynamic Pricing, and Time-} Sensitive Cargo. Slot allocation issue has been widely studied for decades. Maragos [9] made the first step to analyze the feature of liner shipping and considered the problem of the dynamic slot allocation and pricing in both single-segment and multisegment container shipping, while a very important problem in shipping operation management, i.e., the empty container repositioning problem caused by region trade imbalance was, not considered. Feng and Chang [10] and Song and Carter [11] solved the empty container repositioning problem within seaborne shipping networks, while no laden container routing was done explicitly. Feng and Chang [12] studied the optimal slot allocation problem serving a specific shipping service route for ocean carriers and took into account the empty and laden containers allocation. But in their papers, the demand has been assumed to be known and deterministic, while in reality, the demand generally fluctuates and the unknown and uncertain demand is more practical. Considering the demand uncertainty, Bu et al. [13] developed two stochastic programming models on capacity allocation with and without empty containers transportation involved, which were solved by the method of robust optimization. Wang [14] considered the stochastic resource allocation problem for containerized cargo transportation with uncertain capacities and network effects and provided theoretical results about the proposed constrained stochastic programming model. There still exist some studies which discussed the issue of containership slot management from different perspectives. Song and Dong [15], Wang et al. [16], and Guericke and Tierney [17] studied the container routing problem by pathbased in operational level, tactical-level, and strategic level, respectively, or by link-based such as Wang [18] and Wang et al. [19], which are all formulated as multicommodity flow problems and can be used to assess the rationalization of slot utilization.

Considering the dynamic pricing problem, Feng and Xiao [20] addressed the integrated dynamic pricing and capacity allocation problem for perishable products, in which they assumed that the supplier sells the same products to different micromarkets at distinct prices. Taudes and Rudloff [21] proposed a pricing and inventory control model with a two-period linear demand model, proving that the optimal joint pricing/inventory policy for the replenishment opportunity after the first period is a base-stock list-price policy. Zhu [22] studied a single-item periodic-review model for dynamic pricing problem with returns and expediting. Lee [23] studied a periodic-review pricing and inventory replenishment problem with stochastic demands in multiple periods. Liu and Yang [24] proposed a joint slot allocation and dynamic pricing model with demand uncertainties in the container sea-rail multimodal transport system. It can be seen that the dynamic pricing problem are usually multiphase issue with distinct prices.

It is noted that the existing literature made most effort on slot allocation and dynamic pricing of ordinary cargo, mainly about method improvement of the slot allocation. Few studies can be found about slot allocation for timesensitive which has a specific delivery requirement especially for delivery time. According to Panayides and Song [25] and Wang and Meng [26], the "time factor" is a fundamental requirement of practical liner shipping networks, in which port congestion plays an important role. Meng and Wang [27], Wang et al. [16], Wang and Meng [26], and Meng et al. [28] considered transit time to solve the container paths and network design problem. Wang and Meng [29] proposed a mixed-integer nonlinear stochastic model to hedge against uncertain container handling times and port congestion. Wang et al. [30] took port time windows in their nonlinear model to deal with ship route schedule design problem. Readers can refer to [31] for further information on the cargo allocation and scheduling problem. While all of them pay more attention on network design, rather than container slot allocation problem. As for time-sensitive cargo shipping 
demand, Wang et al. [32] and Wang et al. [33] considered the transit-time-sensitive demand which was assumed to be a decreasing continuous function of transit time, to optimal containership schedule as well as the total profit. Also, the path schedule is the main concern in those papers. However, we intend to pay more attention on slot allocation with dynamic pricing problem, which is distinct to the previous studies. Recently, Wang and Li [34] reported the dynamic pricing model for container slot allocation at an international conference.

In conclusion, to the best of our knowledge, the container slot allocation problem with dynamic pricing for time-sensitive cargoes has been hardly studied yet. For timesensitive cargoes, the design of new pricing pattern for freight rate is the main issue we are concerned about, thus we make a correlation between freight rate and delivery time, in which port congestion is taken into account as the major influence factor to delivery time. In addition, most existing researches take the uncertainty of demand of cargo into account and regard the market of cargo as two categories: contract cargo and spot cargo, but rarely take the contract market and spot market of cargoes as a whole system. So, this paper will study the container allocation problem for timesensitive cargoes in which the demand uncertainty and empty transportation caused by imbalanced region trade are two key issues to be involved in our considerations, and a new pricing pattern is designed considering port congestion. This paper will formulate the proposed problem as two different models based on two different points of view and will analyze and discuss the solutions of the two developed models.

2.2. Objectives and Contributions. Through the research reviewed above, we can find that the proposed container slot allocation with dynamic pricing problem for time-sensitive cargo considering port congestion remaining an interesting research issue and is deserved to be taken effort. This paper focuses on this issue and takes time limit of shipping cargo and port congestion into consideration, namely, constructing a correlation between freight rate and delivery time, in which port congestion is one of the main influence factors. The objective is to maximize the total revenue of container shipping company in both contract and spot markets, considering empty containers and demand uncertainties.

The contribution of this paper has four aspects. First, it contributes to the literature of container slot allocation for time-sensitive cargoes, which is of practical significance. Second, it develops a new pricing pattern for a shipping company in which the freight rate is determined based on the service efficiency of the shipping company, namely, the pricing pattern is dynamic not static. Such a pricing pattern motivates the shipping company to provide efficient delivery service and benefits the customers as well. Third, port congestion, which cannot be ignored in nowadays for more and more booming global seaborne trade leading to crowded for ports, is taken into consideration as one of the main influence factors for cargoes' delivery time, and it is of importance for it will further impact the service efficiency as well as the revenue of the shipping company. Fourth, this paper develops a model based on different points of view to contrast the optimal solutions and demonstrates which one is more efficient for the container slot allocation problem, which has not been studied in the existing literature. Finally, the proposed methodology and solution algorithm could also be applied to other similar problem with time limit requirement, such as air transportation planning problem and railway transporting with perishable cargo.

\section{Problem Statement}

This section firstly addresses the shipping route and the container shipment flow and then presents the proposed container slot allocation and dynamic pricing problem for time-sensitive cargo with demand uncertainty in detail, including the slot allocation scheme, the proposed new price mechanism, and two different allocation strategies, and finally describes the notations used in this paper.

3.1. Shipping Route and Container Shipment Flow. The existing studies on container slot allocation problem generally assume the shipping route as a back and forth route separately $[13,24]$, and obviously it is not consistence with the actual situation, in which the shipping route is an itinerary of shipping sailing with the ports of call on the sail. Assume a target container shipping company operates a shipping line which serves a group of ports denoted by the set $\Omega$. The port rotation in the line can be expressed as

$$
p^{1} \longrightarrow p^{2} \longrightarrow p^{3} \longrightarrow \cdots \longrightarrow p^{m} \longrightarrow p^{1}
$$

where $p^{i} \in \Omega(i=1,2, \ldots, m)$ is the $i$ th port of call on the shipping route and $m$ is the number of ports of call.

Let $\Omega=\left\{p^{1}, \ldots, p^{i}, \ldots p^{m}\right\}$ be the set of ports called at the shipping line, and let $\left(p^{i}, p^{j}\right)$ denote the port pair from port $p^{i}$ to port $p^{j}$. The set of $\mathrm{O}-\mathrm{D}$ port pairs having container slot demand can be expressed by $M=\left\{\left(p^{i}, p^{j}\right) \mid i, j=\right.$ $\left.1,2, \ldots, m ; p^{i} \neq p^{j}\right\}$. The container slot demand between O-D port pair $\left(p^{i}, p^{j}\right)$ is uncertain and denoted by a random variable $\xi^{\left(p^{i}, p^{j}\right)}$. A leg $i$ is defined as the voyage from port $p^{i}$ to port $p^{i+1} i=1,2, \ldots, m-1$, and leg $m$ stands for the voyage from port $p^{m}$ to port $p^{1}$. When a ship sails on leg $l(l=1,2, \ldots, m)$ of the itinerary shipping line, the container on the ship includes the newly loaded at port $p^{l}$ and those loaded at previous ports but still remained on ship, which is referred to as container shipment flow on leg $l$, denoted by $\eta_{l}$. Generally, we can express the container shipment flow for a leg $l$ as follows [32]:

$$
\eta_{l}=\sum_{\left(p^{i}, p^{j}\right) \in M} \rho_{l}^{\left(p^{i}, p^{j}\right)} \xi^{\left(p^{i}, p^{j}\right)}, \quad l=1,2, \ldots, m .
$$

3.2. Problem Description. The shipping line operates a shipping route which calls at a total of $m$ ports in sequence in an itinerary line, with slot capacity denoted by $Q$. The 
cargoes transported by the shipping company are all timesensitive ones which call for express delivery as soon as possible. Meanwhile, this study assumes that the transported time-sensitive cargoes are the same one type and have the same requirement to delivery time. Slots are then sold to different kinds of shippers so as to maximize the revenue for the shipping company.

We divide the market into two groups: contract sale market and free sale market (or spot market). It is assumed that the market is relatively stable, that is to say the price in same condition is steady and there exists no risk for contract shipper's transfer to spot market. On one hand in the contract sale market, there are large shippers who have a regular, steady, and high amount of demand and have the bargaining power to acquire the slots with a low price. To ensure stable income, the container shipping company should reserve a large portion of slots for the contract customers. It is important to note that the shipping company determines allocation scheme according its prejudgment on the market referring historical data, and thus the amount of contract sale demand is uncertain. While on the other hand, in the free sale market, scattered shippers do not have bargaining power, and hence they must attain the slots with a series relatively high price associated with booking period. The scattered shippers can book slots during $t$ periods of the whole freight solicitation time $T$, and the price will always go up over time. It is assumed that the demand of free sale in different booking periods' changes with price fluctuations, and the form of demand function is a linear function. The shipping company can divide the freight solicitation time $T$ into $t$ periods, the greater the $t$, the closer it to canvassing deadline, and the less the sensitive of shippers' demand to price changes. With the growth of the price, free sale demand varies inversely with changes which are assumed to be a simple linear relationship. The container slot demand in contract and spot market is assumed to be sufficient, namely, the market is seller's market. With this assumption, the container shipping company has the priority to decide the slot allocation scheme and dynamic pricing with the limited slot resources among shippers. In addition, considering the trade imbalance among ports, there may be empty container demand in some ports, resulting in empty container reposition, which produces cost for the shipping company and is also an issue we must considered when making slot allocation determination.

Without considering the demand that exceeds the capacity of the ship, here we assumed that the container slot capacity $Q$ is big enough for contract cargoes and empty containers, so that there are left slots for scattered shippers. Therefore, the shipping company allocates the $Q$ slots in three aspects. Firstly, a great proportion of the slots are sold in advance with a lower price as a series contract sale negotiated with large shippers in contract sale market. Secondly, considering empty container demand caused by trade imbalance among ports, shipping company must set aside some slots to fulfill the empty container demand of some ports. Third, the remaining slots are sold to the scattered shippers who have no bargaining power in the spot market freely with a series of relatively high price associated with booking period. The container shipping company has to decide the optimal price according to the forecast demand in each booking period and the reallocation of residual slots on each loaded container O-D pair.

3.3. New Price Mechanism for Time-Sensitive Cargo considering Port Congestion. Considering the delivery requirement of time-sensitive cargo on due time, a new price mechanism is designed, in which we make a correlation between freight rate and delivery time, and a penalty/incentive factor is introduced for delivered delay or advance each one day, respectively. Hence, a basis price is set up for time-sensitive cargo delivered just on the agreed delivery time $U^{\left(p^{i}, p^{j}\right)}$ for each loaded container O-D pair $\left(p^{i}, p^{j}\right)$; however, when cargo is delivered in advance, the shipping company will charge an extra fee; on the contrary, if cargo delivered exceeds the time limit, the company should pay certain penalty for the overdue time. Thus, the actual freight rate in final will be the basis price minus a penalty price which equals the penalty factor multiplied by the overdue time, or plus an incentive price which equals the incentive factor multiplied by the advance delivery time.

As to the actual delivery time (or we can say due time), it is mainly concerned with sailing time on board, and the waiting and loading/unloading time on loaded port considering port congestion. As mentioned before, the most common uncontrollable factor is port congestion, which further impacts the total delivery time as well as the actual freight rate. Given that the complexity of influence factors on port congestion, this paper takes queuing theory into account, regarding the port system as an $\mathrm{M} / \mathrm{M} / \mathrm{c}$ system to construct slot allocation models. Suppose that there is finite number of cargo handling equipment in each port, which have independent service time which follows negative exponential distribution, and the ships' arrival with the Poisson process and the time interval between two successive arrivals follows negative exponential distribution. Although in reality, the arrival time of ships are given at least one week in advance, while the information is unknown to the shipping line. Thus, when the shipping line predicts the waiting time at port so as to determine the negotiated delivery time with shippers, the service system can be regarded as an $\mathrm{M} / \mathrm{M} / \mathrm{c}$ queuing system. According to the queuing theory, ship's dwell time in a port, including waiting to be served and service time and also follows a negative exponential distribution.

3.4. Strategies for Slot Allocation. Traditional studies on slot allocation problem usually divide the allocation process into two stages and assign as many as possible container slots to large shippers on contract market to obtain a steady income. However, scattered shippers on spot market are the ones that can provide higher freight rate to get instant service, and certainly high yield means high risk for shipping line. So, it indicates that we need to determine a proper proportion in the allocation scheme, other than giving an absolute preference to contract shippers or determining a proportion artificially. Accordingly, this paper proposes a method based on 
the strategy to deal with the issue of container slot allocation and dynamic pricing process. The method is to take the three parts as a whole system, consider the contract container slots, scattered container slots, and empty container slots together to make the total expected revenue maximize. This paper will construct an optimization model accordingly.

For the expression convenient, the notations used in this paper are listed as follows:

Sets:

Parameters:

Decision variables:

$\Omega$ : set of all ports indexed by $i, \Omega=\left\{p^{i} \mid i=1,2, \ldots, m\right\}$.

M: set of the O-D pairs from port $i$ to port $j$, $M=\left\{\left(p^{i}, p^{j}\right) \mid p^{i} \in \Omega, p^{j} \in \Omega, i \neq j\right\}$.

$p_{a^{0}}^{\left(p^{i}, p^{j}\right)}$ : the negotiated basis price for contract shippers when cargo delivered on time.

$p_{a}^{\left(p^{i}, p^{j}\right)}$ : the actual price for contract shippers, which equals the basis price minus a penalty price when cargo delivery postponed or plus an award price when cargo delivery advanced.

$U^{\left(p^{i}, p^{j}\right)}$ : the expected delivery time for the time-sensitive cargo on O-D pair $\left(p^{i}, p^{j}\right)$, the cargo freight will be basis price when cargo is delivered just in time $U^{\left(p^{i}, p^{j}\right)}$.

$e$ : the penalty or incentive factor for delivered delay or advance one day for each container.

$c^{\left(p^{i}, p^{j}\right)}$ : the cost of transporting an empty container on O-D pair $\left(p^{i}, p^{j}\right)$.

$\Delta t^{\left(p^{i}, p^{j}\right)}$ : sailing time of ship between O-D pair $\left(p^{i}, p^{j}\right)$. $w^{p^{j}}$ : the waiting time caused by port congestion in $p^{j}$, which indicates the dwell time of ship in queuing system including the time waiting for service and the service time, i.e., loading or unloading time. The waiting time follows negative exponential distribution with parameter $\lambda^{p^{j}}$.

$t^{\left(p^{i}, p^{j}\right)}$ : the actual delivery time for cargo from $p^{i}$ to $p^{j}$, which equals $\Delta t^{\left(p^{i}, p^{j}\right)}$ plus $w^{p^{j}}$.

$Q$ : the slot capacity of ship.

$D_{a}^{\left(p^{i}, p^{j}\right)}$ : the random demand of contract shippers on

O-D pair $\left(p^{i}, p^{j}\right)$.

$E^{p^{j}}$ : the empty container demand in $p^{j}$.

$\mathrm{ES}^{p^{i}}$ : the empty container stock in $p^{i}$.

$P_{U}^{\left(p^{i}, p^{j}\right)}$ : the upper limit of basis price for free sale on O-D pair $\left(p^{i}, p^{j}\right)$.

$T$ : the freight solicitation time of free sale.

$t$ : the booking period of free sale.

$\alpha_{t}^{\left(p^{i}, p^{j}\right)}, \beta_{t}^{\left(p^{i}, p^{j}\right)}$ : the coefficients in demand function $x_{b t}^{\left(p^{i}, p^{j}\right)}\left(p_{b^{0} t}^{\left(p^{i}, p^{j}\right)}\right)$, which can be estimated using statistical historical data.

$x_{a}^{\left(p^{i}, p^{j}\right)}$ : the numbers of slots allocated to contract shippers for contract sale on O-D pair $\left(p^{i}, p^{j}\right)$. $x_{c}^{\left(p^{i}, p^{j}\right)}$ : the number of slots allocated to empty containers allocation on O-D pair $\left(p^{i}, p^{j}\right)$.

$p_{b t}^{\left(p^{i}, p^{j}\right)}$ : the actual price in the booking period $t$ of free sale on O-D pair $\left(p^{i}, p^{j}\right)$.

$p_{b^{0} t}^{\left(p^{i}, p^{j}\right)}$ : the basis price for free sale in the booking period $t$ on O-D pair $\left(p^{i}, p^{j}\right)$ when cargo delivered on time.

$x_{b t}^{\left(p^{i}, p^{j}\right)}$ : the slot demand in the booking period $t$ of free sale on O-D pair $\left(p^{i}, p^{j}\right)$, which can be expressed as the function of the basis price $p_{b^{0} t}^{\left(p^{i}, p^{\prime}\right)}$.

$\rho_{a l}^{\left(p^{i}, p^{j}\right)}$ : binary variable, which equals 1 if the contract sale journey of containers of port pair $\left(p^{i}, p^{j}\right)$ contains leg $l(l=1,2, \cdots, \mathrm{m})$ and 0 otherwise.

$\rho_{b l}^{\left(p^{i}, p^{j}\right)}$ : binary variable, which equals 1 if the free sale journey of containers of port pair $\left(p^{i}, p^{j}\right)$ contains leg $l$ $(l=1,2, \cdots, \mathrm{m})$ and 0 otherwise.

$\rho_{c l}^{\left(p^{i}, p^{j}\right)}$ : binary variable, which equals 1 if the journey of empty containers of port pair $\left(p^{i}, p^{j}\right)$ contains leg $l$ $(l=1,2, \cdots, \mathrm{m})$ and 0 otherwise.

$\eta_{a l}$ : slots allocated for contract containers on leg $l$. As mentioned before, it can be expressed as $\eta_{a l}=\sum_{\left(p^{i}, p^{j}\right) \in M} \rho_{a l}^{\left(p^{i}, p^{j}\right)} x_{a}^{\left(p^{i}, p^{j}\right)}, l=1,2, \ldots, m$.

$\eta_{b t l}$ : slots allocated for free sale containers on leg $l$ in the booking period $t$. Thus it can be expressed as $\eta_{b t l}=\sum_{\left(p^{i}, p^{j}\right) \in M} \rho_{b l}^{\left(p^{i}, p^{j}\right)} x_{b t}^{\left(p^{i}, p^{j}\right)}, l=1,2, \ldots, m$.

$\eta_{c l}$ : slots allocated for empty containers on leg $l$. As described before, it can be expressed as $\eta_{c l}=\sum_{\left(p^{i}, p^{j}\right) \in M} \rho_{c l}^{\left(p^{i}, p^{j}\right)} x_{c}^{\left(p^{i}, p^{j}\right)}, l=1,2, \ldots, m$.

\section{Model Development}

4.1. Chance Constraints for Container Demand Uncertainty. In this paper, the uncertainty of container slot demand is taken into consideration, which makes the slot allocation problem more complex and more realistic due to the existence of random demand variables $D_{a}^{\left(p^{i}, p^{j}\right)}$, whereas results no decisions would definitely exclude later constraint violation caused by unexpected random effects. Since decisions derived under adverse conditions may not fully meet the requirement for its customers, it makes sense for container shipping company to control the possibility of the case at a low level, namely, only a low percentage of realizations of the random parameter of shipment demand leads to constrain violation under the determined and fixed decision. Therefore, the chance constrained programming (CCP) method, proposed by Charnes and Cooper [35], is utilized in this paper to formulate the constraint violation.

In the chance constrained programming model, given the confidence parameter $\alpha \in(0,1)$, the container shipping company can satisfy the customers' demand with a possibility of $1-\alpha$, which can be formulated in the following probabilistic form:

$$
\operatorname{Pr}\left(x_{a}^{\left(p^{i}, p^{j}\right)} \leq D_{a}^{\left(p^{i}, p^{j}\right)}\right) \geq 1-\alpha, \quad \forall\left(p^{i}, p^{j}\right) \in M .
$$


Equation (3) is a chance constraint. By taking into account the demand uncertainty, the shipping company can guarantee decision-making feasibility. And also, the shipping company can control its chance facing the risk resulting from uncontrollable and unpredicted factors with the range of $\alpha$.

4.2. Model I: One-Phase Allocation Model (1PAM). With the consideration of container slot demand uncertainty and the new price mechanism caused by the attribute of time-sensitive cargo, there is a need to build a mathematical model for the container shipping company to handle the issue so as to maximum the revenue. Through the new price mechanism, the actual price of time-sensitive cargo for contract and scattered shippers can be expressed by equations (4) and (5), respectively, in which the items in parentheses represent the difference between actual delivery time (the sum of sailing time and service time) and negotiated time for cargo from $p^{i}$ to $p^{j}$ :

$$
\begin{aligned}
& p_{a}^{\left(p^{i}, p^{j}\right)}=p_{a^{0}}^{\left(p^{i}, p^{j}\right)}-\left(\Delta t^{\left(p^{i}, p^{j}\right)}+w^{p^{j}}-U^{\left(p^{i}, p^{j}\right)}\right) \times e, \quad \forall\left(p^{i}, p^{j}\right) \in M, \\
& p_{b t}^{\left(p^{i}, p^{j}\right)}=p_{b^{0} t}^{\left(p^{i}, p^{j}\right)}-\left(\Delta t{\left(p^{i}, p^{j}\right)}+w^{p^{j}}-U^{\left(p^{i}, p^{j}\right)}\right) \times e, \quad \forall\left(p^{i}, p^{j}\right) \in M, \forall t .
\end{aligned}
$$

According to the description of the first method, we consider the slot allocation as a whole to construct model I. The model I is a one-phase allocation model, in which the slot allocation system is taken as an entirety, and the objective is to maximize the whole revenue. The model is formulated as a chance constrained stochastic integer programming with dynamic pricing:

$$
\max Z=\sum_{\left(p^{i}, p^{j}\right) \in M} p_{a}^{\left(p^{i}, p^{j}\right)} x_{a}^{\left(p^{i}, p^{j}\right)}+\sum_{t=1}^{T} \sum_{\left(p^{i}, p^{j}\right) \in M} p_{b t}^{\left(p^{i}, p^{j}\right)} x_{b t}^{\left(p^{i}, p^{j}\right)}-\sum_{\left(p^{i}, p^{j}\right) \in M} c^{\left(p^{i}, p^{j}\right)} x_{c}^{\left(p^{i}, p^{j}\right)}
$$

subject to

$$
\begin{gathered}
x_{b t}^{\left(p^{i}, p^{j}\right)}=\alpha_{t}^{\left(p^{i}, p^{j}\right)}-\beta_{t}^{\left(p^{i}, p^{j}\right)} p_{b^{0} t}^{\left(p^{i}, p^{j}\right)}, \quad \forall\left(p^{i}, p^{j}\right) \in M, \forall t \\
p_{a^{0}}^{\left(p^{i}, p^{j}\right)} \leq p_{b^{0} t}^{\left(p^{i}, p^{j}\right)} \leq P_{U}^{\left(p^{i}, p^{j}\right)}, \quad \forall\left(p^{i}, p^{j}\right) \in M, \forall t \\
\eta_{a l}+\sum_{t=1}^{T} \eta_{b t l}+\eta_{c l} \leq Q, \quad \forall l=1,2, \ldots, m \\
\operatorname{Pr}\left(x_{a}^{\left(p^{i}, p^{j}\right)} \leq D_{a}^{\left(p^{i}, p^{j}\right)}\right) \geq 1-\alpha, \quad \forall\left(p^{i}, p^{j}\right) \in M \\
\sum_{\left(p^{i}, p^{j}\right) \in M} x_{c}^{\left(p^{i}, p^{j}\right)} \geq E^{p^{j}}, \quad \forall p^{j} \in \Omega, \\
x_{c}^{\left(p^{i}, p^{j}\right)} \leq \mathrm{ES}^{p^{i}}, \quad \forall p^{i} \in \Omega, \\
x_{c}^{\left(p^{j}, p^{k}\right)}=0, \text { when } E^{p^{j}}>0, \quad \forall p^{j}, p^{k} \in \Omega \\
x_{a}^{\left(p^{i}, p^{j}\right)}, x_{b t}^{\left(p^{i}, p^{j}\right)}, x_{c}^{\left(p^{i}, p^{j}\right)} \in N \cup\{0\}, \quad \forall\left(p^{i}, p^{j}\right) \in M
\end{gathered}
$$

Equation (6) is the objective function of this model, in which the first term is the profit of shipping contract cargoes, and the second term is the revenue of cargos from scattered shippers in all booking periods of free sale; finally, the last term is the cost of empty containers transportation, which must be deducted from the company's total revenue. The set of constraints (7) indicates the linear relation between price and demand in free market. The set of constraints (8) ensures that the basis price in free market is in any period and cannot be less than the basis price of contract sale and cannot be more than a price upper limit on each O-D pair. The set of constraints (9) requires that the total number of slot allocated to the contract shippers, the scattered shippers, and the empty containers cannot exceed the capacity of the ship. The set of constraints (10) is a chance constraint to define that the slots reserved for contract shippers can be efficiently used, namely, the probability of the slots allocated to contract shippers exceed the actual demand, the situation in which the shipping company suffers opportunity loss, is less than $\alpha$. Constraint set (11) presents the empty container slot allocation from each $p^{i}$ to $p^{j}$ cannot be less than the empty container demand of $p^{j}$. Constraint set (12) presents the empty containers transporting from $p^{i}$ to $p^{j}$ cannot be more than the available empty containers in port $p^{i}$. While constraint set (13) indicates that the empty container cannot be transported from $p^{j}$ to the other ports when $p^{j}$ has an empty container demand. Constraint (14) is an integer constraint of the decision variables. 


\section{Two Key Challenges in Solving the Stochastic Optimization Model}

There are mainly two key difficulties in solving the proposed stochastic optimization model. Due to the existence of uncertain demand in contract market and the random variables of waiting time caused by port congestion, the proposed models are nondeterministic optimization problems and intractable to deal with. In this section, the chance constraint programming and Jensen's inequality are introduced, respectively, to make a transformation of the models.

5.1. Solving the Chance Constraints in Model. The most difficulty in the model is how to deal with the chance constraints. Here, we assume that the demand of contract sale is a random value following log-normal distribution and the demand on each O-D pair is independent. Previous studies mostly assumed that the demand follows normal distribution, which inevitably leads to some negative values when use the normal distribution to generate a sample; obviously, the negative demand is unrealistic. Whereas the log-normal assumption effectively overcomes this shortcoming of normal distribution, and it is proved by Kamath and Pakkala [36] that the log-normal distribution is well suited for modeling economic stochastic variables such as demand. Therefore, we assume the demand in each O-D pair follows log-normal distribution, i.e., $D_{a}^{\left(p^{i}, p^{j}\right)} \sim \ln N$ $\left(\mu^{\left(p^{i}, p^{j}\right)}, \sigma^{\left(p^{i}, p^{j}\right)}\right)$, and they are independent from each other.

Under the precondition of this hypothesis, we can express the set of chance constraints given by equation (11) with the equivalence deterministic constraints, where $\left(\Phi^{\left(p^{i}, p^{j}\right)}\right)^{-1}$ is the inverse function of the distribution function $\Phi^{\left(p^{i}, p^{j}\right)}$ of $D_{a}^{\left(p^{i}, p^{j}\right)}$ :

$$
x_{a}^{\left(p^{i}, p^{j}\right)} \leq Z_{1-\alpha}=\sup \left\{Z \mid Z=\left(\Phi^{\left(p^{i}, p^{j}\right)}\right)^{-1}(1-\alpha)\right\}, \quad \forall\left(p^{i}, p^{j}\right) \in M .
$$

Thus, the chance constraints (10) can be replaced by equation (15), and then the model can be transformed into quadratic programming problem with linear constraints and can be solved efficiently by the program solver.

\subsection{Solving the Random Variables of Waiting Time in Model.} Another difficult problem encountered by the model is how to deal with the random variables of waiting time, which makes the model become a nondeterministic optimization problem. To solve this problem, two aspects of the measures are taken as follows.

Firstly, considering the randomness of the waiting time, $N$ tests are implemented to get the general tendency of the model, so as to compare their robustness. In each test, the only optimal solution is obtained under the deterministic value of waiting time. After $N$ tests, the model which gets relatively stable results has higher robustness than the other one.
Secondly, to get the exact optimal solution for the proposed model, we can use the Jensen's inequality proposed by Wallace and Fleten [37] to transfer the model into deterministic optimization models. They proved that for any $x$, if $F(x, W)$ is concave in $W$, where $W$ is a random variable with its mean $\lambda=E[W]$, then the following Jensen's inequality holds:

$$
F(x, \lambda) \geq E[F(x, W)]
$$

Hence

$$
\max _{x \geq 0} F(x, \lambda) \geq \max _{x \geq 0} E[F(x, W)] .
$$

Thus, the optimal value of the deterministic optimization problem is biased upward relative to the optimal value of the stochastic optimization problem. In our model, the waiting time $w^{p^{j}}$ is a random variable with its mean $\lambda^{p^{j}}$. In both objective functions (6) and (16), $p_{a}^{\left(p^{i}, p^{j}\right)}$ is concave with $w^{p^{j}}$. Thus the two functions are both concave in $w^{p^{j}}$, which is a random variable with its mean $\lambda^{p^{j}}$. Therefore, we can replace the random variable $w^{p^{j}}$ with its mean $\lambda^{p^{j}}$, and then the models can be solved by deterministic optimization problem.

As a consequence, when the two key difficulties are treated by the methods described in Section 4.1 and Section 4.2 , the proposed model is transformed into a model with deterministic forms, which can be efficiently solved by any optimization solver provided by Matlab. Hence, the optimal slot allocation strategy can be obtained by solving the model.

\section{Numerical Experiment and Computational Results}

Here, an example is implemented to assess the model of slot allocation for time-sensitive cargo and the solution algorithm developed for solving the slot allocation problem with uncertain demand.

6.1. Numerical Experiment. In the case, the container ship route calls at three ports clockwise with order $p^{1} \longrightarrow p^{2} \longrightarrow p^{3} \longrightarrow p^{1}$ and serves six O-D port pairs, with the slot capacity $Q=5000$ TEUs. It is assumed that slot demand of contract shippers for each port pair has been obtained through historical data, which is a random variable following log-normal distribution, i.e., $D_{a}^{\left(p^{i}, p^{j}\right)} \sim \ln N$ $\left(\mu^{\left(p^{i}, p^{j}\right)}, \sigma^{\left(p^{i}, p^{j}\right)}\right)$, with parameters shown in Table 1 . It is noted that previous studies mostly assumed that the demand follows normal distribution, which inevitably leads to some negative values when use the normal distribution to generate a sample, and obviously the negative demand is unrealistic. Whereas the log-normal assumption effectively overcomes this shortcoming of normal distribution and it is proved by Kamath and Pakkala [36] that the log-normal distribution is well suited for modeling economic stochastic variables such as demand.

The data of the basis price of contract sale on each loaded container O-D pair $\left(p^{i}, p^{j}\right)$ and the cost of transporting an 
TABLE 1: Basis price and demand of contract sale and cost and demand of empty container transportation.

\begin{tabular}{|c|c|c|c|c|c|c|c|}
\hline O-D pair $\left(p^{i}, p^{j}\right)$ & & $\left(p^{1}, p^{2}\right)$ & $\left(p^{1}, p^{3}\right)$ & $\left(p^{2}, p^{1}\right)$ & $\left(p^{2}, p^{3}\right)$ & $\left(p^{3}, p^{1}\right)$ & $\left(p^{3}, p^{2}\right)$ \\
\hline \multirow{4}{*}{ Contract sale } & $p_{a^{0}}^{\left(p^{i}, p^{j}\right)}$ & 1250 & 2820 & 2680 & 1970 & 1130 & 1860 \\
\hline & $\mu^{\left(p^{i}, p^{j}\right)}$ & 1870 & 1100 & 990 & 2052 & 1918 & 1285 \\
\hline & $\sigma^{\left(p^{i}, p^{j}\right)}$ & 120 & 115 & 78 & 110 & 109 & 130 \\
\hline & $c^{\left(p^{i}, p^{j}\right)}$ & 155 & 360 & 345 & 250 & 135 & 275 \\
\hline Empty container & $\begin{aligned} & E^{p^{j}} \\
& \mathrm{ES}^{p^{i}}\end{aligned}$ & \multicolumn{2}{|c|}{$\begin{array}{c}E_{1}=0 \\
\mathrm{ES}_{1}=400\end{array}$} & \multicolumn{2}{|c|}{$\begin{array}{c}E_{2}=380 \\
\mathrm{ES}_{2}=0\end{array}$} & \multicolumn{2}{|c|}{$\begin{array}{c}E_{3}=0 \\
\mathrm{ES}_{3}=200\end{array}$} \\
\hline
\end{tabular}

TABle 2: Data about delivery time.

\begin{tabular}{lccccccc}
\hline O-D pair $\left(p^{i}, p^{j}\right)$ & & $\left(p^{1}, p^{2}\right)$ & $\left(p^{1}, p^{3}\right)$ & $\left(p^{2}, p^{1}\right)$ & $\left(p^{2}, p^{3}\right)$ & $\left(p^{3}, p^{1}\right)$ & $\left(p^{3}, p^{2}\right)$ \\
\hline \multirow{3}{*}{ Delivery time } & $\Delta t^{\left(p^{i}, p^{j}\right)}$ (day) & 5.5 & 13 & 11.5 & 7 & 4 \\
& $U^{\left(p^{i}, p^{j}\right)}$ & 6 & & 15 & 13.5 & 8.5 & 4.5 \\
& $\lambda^{p^{j}}$ (hour) & & 5 & & & 16 & 11.5 \\
\hline
\end{tabular}

TABLe 3: Estimation and variation of demand function coefficients and price limit in free market.

\begin{tabular}{cccccccc}
\hline O-D pair $\left(p^{i}, p^{j}\right)$ & $\left(p^{1}, p^{2}\right)$ & $\left(p^{1}, p^{3}\right)$ & $\left(p^{2}, p^{1}\right)$ & $\left(p^{2}, p^{3}\right)$ & $\left(p^{3}, p^{1}\right)$ & $\left(p^{3}, p^{2}\right)$ \\
\hline \multirow{2}{*}{$t=1$} & $\alpha_{t}^{\left(p^{i}, p^{j}\right)}$ & 750 & 675 & 695 & 620 & 675 & 550 \\
& $\beta_{t}^{\left(p^{i}, p^{j}\right)}$ & 0.36 & 0.19 & 0.20 & 0.25 & 0.4 \\
$t=2$ & $\alpha_{t}\left(p^{i}, p^{j}\right)$ & 770 & 655 & 705 & 630 & 680 \\
$P_{U}^{\left(p^{i}, p^{j}\right)}$ & $\beta_{t}^{\left.p^{i}, p^{j}\right)}$ & 0.37 & 0.18 & 0.19 & 0.25 & 560 \\
\hline
\end{tabular}

The confidence parameter $\alpha=0.05$.

empty container on each O-D pair $\left(p^{i}, p^{j}\right)$ are presented in Table 1.

Here, we set the penalty or incentive factor $e=500$ dollars per day for each TEU. The sailing time between O-D port pair is obtained from the schedule. And, $U^{\left(p^{i}, p^{j}\right)}$ is given according to cargo's property and distance of $\mathrm{O}-\mathrm{D}$ port pair. Waiting time is given based on port service efficiency, and the arrival rate of the ship. The data are shown in Table 2.

It is assumed that freight solicitation time of free sale is divided into 2 periods, $t=1$ represents that the slots are reserved two weeks in advance; $t=2$ represents that the slots are reserved one weeks in advance. The greater the $t$, the closer it is to canvassing deadline, and less sensitive the shippers' demand to price changes. Through statistical analysis of relevant data, the estimation and variation of demand function coefficients in different periods on each loaded container O-D pair are presented in Table 3.

6.2. Result Analysis. According to Jensen's inequality, we transfer the model into a deterministic optimization model. We use the average of the waiting time to replace the random waiting time; therefore, we can obtain the result of the model in detail. The optimal solutions are shown in Table 4:

Based on the results, first, we can have a look on the whole, and the optimal total revenue in our model is $2.3797 \times 10^{7}$. Thus, the results are close in the model and the result obtained from the model is good. Obviously, we can see that the slot allocation revenue gained from the contract market and empty container in the model is lower than that benefited from the free market income. A reasonable explanation behind such a result is that the container demand in contract and spot market is assumed to be sufficient, namely, the market is seller's market. Therefore, our model takes the market system as a whole, all shippers including contract shippers and spot ones compete freely, and the higher-price-offer ones can be allocated container slots. No matter how the actual price changes mainly caused by waiting time, our model will preferentially assign the slots to the higher-price-offer ones.

To demonstrate the efficiency of the price mechanism proposed in this paper, we will compare the results in Tables 4 and 5 with the results obtained from the general slot allocation models without considering the time limit of cargo and port congestion, namely, take the basis price in this paper as the actual price in objective functions.

Furthermore, we can extrapolate that the longer the waiting time is, the higher probability that the revenue acquired in new price mechanism is lower than the one attained in basis price. Because with the increase of the waiting time in discharging port, the shipping company will face a higher risk of delays in delivery for time-sensitive cargo, and a penalty will incur for delivered delay. As a consequence, the shipping company must determine under which circumstances should this new pricing strategybe adopted. For example, when the port of call is much congested, it is obviously unwise to consider the new pricing mechanism, which will result heavy loss for shipping company in this condition. 
TABLE 4: Results of slot allocation and actual price for Model I.

\begin{tabular}{|c|c|c|c|c|c|c|c|c|c|}
\hline O-D pair $\left(p^{i}, p^{j}\right)$ & & & $\left(p^{1}, p^{2}\right)$ & $\left(p^{1}, p^{3}\right)$ & $\left(p^{2}, p^{1}\right)$ & $\left(p^{2}, p^{3}\right)$ & $\left(p^{3}, p^{1}\right)$ & $\left(p^{3}, p^{2}\right)$ & Revenue \\
\hline \multirow{3}{*}{ Contract market } & Actu & price & 1167 & 3570 & 3576 & 2470 & 1276 & 2277 & \multirow{3}{*}{$1.9929 \times 10^{7}$} \\
\hline & Number o & lots (TEU) & 1538 & 1118 & 1005 & 2069 & 1935 & 1304 & \\
\hline & & Basis price & 1666 & 2930 & 2750 & 1970 & 1286 & 1990 & \\
\hline \multirow{5}{*}{ Free market } & $t=1$ & Actual price & 1583 & 3680 & 3646 & 2470 & 1432 & 2407 & $1.8746 \times 10^{6}$ \\
\hline & & Slots (TEU) & 150 & 118 & 145 & 128 & 161 & 53 & \\
\hline & & Basis price & 1666 & 2973 & 2868 & 1970 & 1337 & 2057 & \multirow{5}{*}{$2.0520 \times 10^{6}$} \\
\hline & $t=2$ & Actual price & 1583 & 3723 & 3764 & 2470 & 1483 & 2474 & \\
\hline & & Slots (TEU) & 153 & 120 & 160 & 138 & 172 & 66 & \\
\hline Empty container & Slots (TEU) & 380 & 0 & 0 & 0 & 0 & 0 & 0 & \\
\hline \multicolumn{9}{|c|}{ Total revenue: $2.3797 \times 10^{7}$} & \\
\hline
\end{tabular}

TABLE 5: Results of slot allocation just considering basis price in Model I.

\begin{tabular}{|c|c|c|c|c|c|c|c|c|c|}
\hline O-D pair $\left(p^{i}, p^{j}\right)$ & & & $\left(p^{1}, p^{2}\right)$ & $\left(p^{1}, p^{3}\right)$ & $\left(p^{2}, p^{1}\right)$ & $\left(p^{2}, p^{3}\right)$ & $\left(p^{3}, p^{1}\right)$ & $\left(p^{3}, p^{2}\right)$ & Revenue \\
\hline Contract market & \multicolumn{2}{|c|}{ Slots (TEU) } & 1708 & 1118 & 1005 & 2069 & 1935 & 1184 & $1.6446 \times 10^{7}$ \\
\hline \multirow{3}{*}{ Free market } & \multirow{2}{*}{$t=1$} & Price & 1666 & 3016 & 2680 & 1970 & 1149 & 2030 & \multirow{2}{*}{$1.5701 \times 10^{6}$} \\
\hline & & Slots (TEU) & 150 & 102 & 159 & $\begin{array}{c}128 \\
1970\end{array}$ & 215 & 43 & \\
\hline & $t=2$ & Slots (TEU) & $\begin{array}{c}1000 \\
154\end{array}$ & $\begin{array}{l}5059 \\
104\end{array}$ & $\begin{array}{l}2714 \\
178\end{array}$ & $\begin{array}{c}19 / 0 \\
138\end{array}$ & $\begin{array}{c}1200 \\
224\end{array}$ & $\begin{array}{c}2097 \\
57\end{array}$ & $1.7287 \times 10^{6}$ \\
\hline \multirow[t]{2}{*}{ Empty container } & Slots (TEU) & 380 & 0 & 0 & 0 & 0 & 0 & 0 & $-5.8900 \times 10^{4}$ \\
\hline & \multicolumn{8}{|c|}{ Total revenue: $1.9686 * 10^{7}$} & \\
\hline
\end{tabular}

\section{Conclusions}

This paper focuses on time-sensitive cargo transportation, and a new price mechanism is proposed considering the time limit of time-sensitive cargo and port congestion of $\mathrm{O}-\mathrm{D}$ port pairs to make a correlation between freight charge and delivery time when determining cargo freight. Then, a one-phase allocation model is proposed to solve the container slot allocation with dynamic pricing problem for time-sensitive cargo considering port congestion.

The model considers the revenue in a whole system, namely, considering the contract container slots, scattered container slots and empty container slots demand together to make the total expected revenue maximize. The chance constrained programming method is used to deal with the demand uncertainty issue, and Jensen's inequality proposed by Wallace S W et al. (2003) is introduced to solve the random variable waiting time.

Then, a numerical example of slot allocation for timesensitive cargo is carried out to test the applicability of the proposed models and solution algorithm. Additionally, it is proved that the new price mechanism is efficient by comparing with the general slot allocation model without considering the time limit of cargo and port congestion, and the result indicates that the proposed pricing pattern can significantly increase the revenue of shipping company and enhance customer satisfaction.

However, the conclusions are based on the assumption that the container demand in contract and spot market is sufficient, thus the model performance show good robustness. Hence, the shipping company needs to select container slot allocation model according to the market condition or uses Model I to determine the slots proportion reserved for contract shippers who have steady demand.
This study is a preliminary exploration on the pricing pattern of time-sensitive cargo shipping freight in container slot allocation. Although muck work has been done, there still exist some limitations in this paper. Firstly, the timesensitive cargo studied in this paper limits to one kind of cargo with the same time limit demand during the same O-D pair, while there usually exist several different kinds of cargo to deliver in the same ship in reality, which have different time limit demands during the same O-D pair. Thus, the future research direction is suggested to take different categories of cargoes into account, so as to make the study more practical. Secondly, container slot allocation for complex transport routes based on network needs to be further studied. Thirdly, another extension study can focus on pricing mechanism parameter design, such as how to determine a reasonable penalty or incentive factor to make revenue maximization and the effects that the extent of port congestion made on the efficiency of the new pricing mechanism. These aspects are the future study directions which are deserved to take effort on.

\section{Data Availability}

The data used to support the study are available from the corresponding author upon request.

\section{Conflicts of Interest}

The authors declare that they have no conflicts of interest.

\section{Acknowledgments}

The authors thank Dr. Wang from Wuhan University for his suggestions. This study was supported by the Research and 
Innovation Platform Construction Plan of Wuhan College (Grant no. KYP201901) and Fundamental Research Funds for the Central Universities (Grant no. CCNU19TS078).

\section{References}

[1] L. Song, D. Yang, A. T. H. Chin et al., "A game-theoretical approach for modeling competitions in a maritime supply chain," Maritime Policy \& Management, vol. 43, no. 8, pp. 976-991, 2016.

[2] D. Mao and A. T. H. Chin, "Impact of politics, economic events and port policies on the evolution of maritime traffic in Chinese ports," Maritime Policy \& Management, vol. 41, no. 4, pp. 346-366, 2014.

[3] D. Chen, G. P. Ong, and A. T. H. Chin, "An exploratory study on the effect of trade data aggregation on international freight mode choice," Maritime Policy \& Management, vol. 41, no. 3, pp. 212-223, 2014.

[4] UNCTAD, Review of Maritime Transportation: Paper Presented at the United Nations Conference on Trade and Development, UNCTAD, New York, NY, USA, 2016, http:// unctad.org/en/PublicationsLibrary/rmt2016_en.pdf.

[5] M. R. Brooks and T. Schellinck, "Measuring port effectiveness: what really determines cargo interests' evaluations of port service delivery?" Maritime Policy \& Management, vol. 42, no. 7, pp. 699-711, 2015.

[6] Y. Wan, C. L. Yuen, and A. Zhang, "Effects of hinterland accessibility on us container port efficiency," International Journal of Shipping \& Transport Logistics, vol. 6, no. 4, 2014.

[7] X. T. Shang, J. X. Cao, and J. Ren, "A robust optimization approach to the integrated berth allocation and quay crane assignment problem," Transportation Research Part E: Logistics and Transportation Review, vol. 94, pp. 44-65, 2016.

[8] C. Jiang, Y. Wan, and A. Zhang, "Internalization of port congestion: strategic effect behind shipping line delays and implications for terminal charges and investment," Maritime Policy \& Management, pp. 1-19, 2016.

[9] S. A. Maragos, Yield Management for the Maritime Industry, Massachusetts Institute of Technology, Cambridge, MA, USA, 1994.

[10] C.-M. Feng and C.-H. Chang, "Empty container reposition planning for intra-asia liner shipping," Maritime Policy \& Management, vol. 35, no. 5, pp. 469-489, 2008.

[11] D.-P. Song and J. Carter, "Empty container repositioning in liner shipping1," Maritime Policy \& Management, vol. 36, no. 4, pp. 291-307, 2009.

[12] C. M. Feng and C. H. Chang, "Optimal slot allocation with empty container reposition problem for Asia ocean carriers," International Journal of Shipping and Transport Logistics, vol. 2, no. 1, pp. 22-43, 2010.

[13] X. Z. Bu, Q. W. Zhao, Q. Huang et al., "Optimal capacity allocation model of ocean shipping container revenue management considering empty container transportation," Chinese Journal of Management Science, vol. 13, no. 1, pp. 71-75, 2005.

[14] X. Wang, "Stochastic resource allocation for containerized cargo transportation networks when capacities are uncertain," Transportation Research Part E: Logistics and Transportation Review, vol. 93, pp. 334-357, 2016.

[15] D.-P. Song and J.-X. Dong, "Cargo routing and empty container repositioning in multiple shipping service routes," Transportation Research Part B: Methodological, vol. 46, no. 10, pp. 1556-1575, 2012.
[16] S. Wang, Q. Meng, and Z. Sun, "Container routing in liner shipping," Transportation Research Part E: Logistics and Transportation Review, vol. 49, no. 1, pp. 1-7, $2013 \mathrm{~b}$.

[17] S. Guericke and K. Tierney, "Liner shipping cargo allocation with service levels and speed optimization," Transportation Research Part E: Logistics and Transportation Review, vol. 84, pp. 40-60, 2015.

[18] S. Wang, "A novel hybrid-link-based container routing model," Transportation Research Part E: Logistics and Transportation Review, vol. 61, no. 1, pp. 165-175, 2014.

[19] T. Wang, Z. Xing, H. Hu, and X. Qu, "Overbooking and delivery-delay-allowed strategies for container slot allocation," Transportation Research Part E: Logistics and Transportation Review, vol. 122, pp. 433-447, 2019.

[20] Y. Feng and B. Xiao, "Integration of pricing and capacity allocation for perishable products," European Journal of Operational Research, vol. 168, no. 1, pp. 17-34, 2006.

[21] A. Taudes and C. Rudloff, "Integrating inventory control and a price change in the presence of reference price effects: a twoperiod model," Mathematical Methods of Operations Research, vol. 75, no. 1, pp. 29-65, 2012.

[22] S. X. Zhu, "Joint pricing and inventory replenishment decisions with returns and expediting," European Journal of Operational Research, vol. 216, no. 1, pp. 105-112, 2012.

[23] J. Lee, "Dynamic pricing inventory control under fixed cost and lost sales," Applied Mathematical Modelling, vol. 38, no. 2, pp. 712-721, 2014.

[24] D. Liu and H. Yang, "Joint slot allocation and dynamic pricing of container sea-rail multimodal transportation," Journal of Traffic and Transportation Engineering (English Edition), vol. 2, no. 3, pp. 198-208, 2015.

[25] P. M. Panayides and D.-W. Song, "Maritime logistics as an emerging discipline," Maritime Policy \& Management, vol. 40, no. 3, pp. 295-308, 2013.

[26] S. Wang and Q. Meng, "Liner shipping network design with deadlines," Computers \& Operations Research, vol. 41, pp. 140-149, 2014.

[27] Q. Meng and S. Wang, "Optimal operating strategy for a longhaul liner service route," European Journal of Operational Research, vol. 215, no. 1, pp. 105-114, 2011.

[28] Q. Meng, T. Wang, and S. Wang, "Multi-period liner ship fleet planning with dependent uncertain container shipment demand," Maritime Policy \& Management, vol. 42, no. 1, pp. 43-67, 2015.

[29] S. Wang and Q. Meng, "Robust schedule design for liner shipping services," Transportation Research Part E: Logistics and Transportation Review, vol. 48, no. 6, pp. 1093-1106, 2012.

[30] S. Wang, A. Alharbi, and P. Davy, "Liner ship route schedule design with port time windows," Transportation Research Part C: Emerging Technologies, vol. 41, pp. 1-17, 2014.

[31] Q. Meng, S. Wang, H. Andersson, and K. Thun, "Containership routing and scheduling in liner shipping: overview and future research directions," Transportation Science, vol. 48, no. 2, p. 265, 2014.

[32] S. Wang, Q. Meng, and Z. Liu, "Containership scheduling with transit-time-sensitive container shipment demand," Transportation Research Part B: Methodological, vol. 54, no. 3, pp. 68-83, 2013a.

[33] S. Wang, Q. Meng, and C.-Y. Lee, "Liner container assignment model with transit-time-sensitive container shipment demand and its applications," Transportation Research Part B: Methodological, vol. 90, pp. 135-155, 2016. 
[34] T. Wang and M. Li, "Dynamic pricing model for container slot allocation considering port congestion," Smart Innovation, Systems and Technologies, vol. 149, pp. 243-250, 2019.

[35] A. Charnes and W. W. Cooper, "Chance-constrained programming," Management Science, vol. 6, no. 1, pp. 73-79, 1959.

[36] K. R. Kamath and T. P. M. Pakkala, "A Bayesian approach to a dynamic inventory model under an unknown demand distribution," Computers \& Operations Research, vol. 29, no. 4, pp. 403-422, 2002.

[37] S. W. Wallace and S.-E. Fleten, "Stochastic programming models in energy," Handbooks in Operations Research and Management Science, vol. 10, pp. 637-677, 2003. 